\title{
Integrating Biometrics into Police Information Management System: A Case of Zambia Police
}

\author{
G. Lyoko, J. Phiri, and A. Phiri
}

\begin{abstract}
The business processes in the security wings of most developing countries are not automated. This results in loss of documentation, difficulties in looking up documents and tedious reporting. In this study, a baseline study was carried out to ascertain the levels of formal education, Information and Communications Technology (ICT) skills and ICT tools utilization within the Zambia Police Service. Results showed that $47 \%$ have graduated from college, $32 \%$ completed high school and $21 \%$ had attained graduate or postgraduate degrees. In addition, $24 \%$ had received basic computer training. The survey also revealed that $39 \%$ of the respondents use their personal email for work related communications. The study also aimed at establishing the major business processes. Using the business process results from the baseline study, a model was developed. The model was used to develop a web-based prototype by integrating fingerprint biometrics. Captured fingerprint images were pre-processed using wavelet scalar quantization (WSQ) algorithm, the minutiae were extracted and a template generated using Delaunay algorithm. The developed system showed improved business process through automation.
\end{abstract}

Index Terms-Biometrics, ICT, information management system, police.

\section{INTRODUCTION}

The Zambia Police Service, like most third world countries, currently operates using paper based mechanisms. This results in volatility of evidence in the case where important documents are lost. In addition to this, there is loss of traceability, transparency and accountability. The capture and storage of biometric data is also done using paper systems. This makes comparison of biometric data less efficient in comparison to automated processes. Although this has been in use for a long time, the operations can be greatly enhanced through electronic means.

In this study, we propose a software prototype for the Zambia Police Service for automating some of their business processes. To this effect, a number of business processes were identified through a series of interviews with police officers. The identified business processes were the basis of the developed software prototype.

Secondly, a baseline survey was carried out that aimed to gauge the institutional capacity for the police to manage an Information System (IS). The levels of education within the police was determined as well as their Information and Communications Technology (ICT) skills. Additionally, information about how ICTs are used in their work

Manuscript received September 2, 2015; revised December 8, 2015.

The authors are with the Department of Computer Science and the Department of Electronics and Electrical Engineering, University of Zambia, Lusaka, Zambia (e-mail: glyoko@gmail.com). environments was collected.

\section{LITERATURE REVIEW}

\section{A. Background Information}

There has been a recent increase in the usage of ICT in various sectors of the economies in the third world countries. Some of these sectors include Finance, Education and Health among others [1]-[3]. One area that is still not widely exploited is the security wings. This may be due to the sensitivity of the data involved.

The use of manual mechanisms in the police poses a number of challenges that are common to most third world countries. These challenges include low capacity for case tracking, lack of searchable crime databases, lack of detection of unauthorized evidence tampering and retrospective reporting that can be used for decision making and crime profiling [4]. In addition, challenges include management of paper documents and filing which may result in data loss, unauthorized access and damage [5].

Some of the benefits of using ICT include improved service delivery [6]. Another is lower operation costs over time [7]. Other benefits include centralized and easy access to information that can easily be used for decision making, efficiency in operations [4] and lower chances of losing data with proper backup mechanisms in place.

Despite these benefits, there are some challenges in implementing ICTs. One big challenge is the significant initial cost of deploying a technology and sometimes maintenance [7]. This often requires acquiring new equipment and accompanying software. The software may come with long term software contracts. One other challenge is human resource resistance to change [7]. Due to the fact that the workforce will have to use the new technology, it follows that they should be willing to adopt new technologies. However, this is not always the case.

Information Management Systems (IMS) are some of the most commonly used methods of managing business processes within big organizations. A number of systems already exist that are aimed at helping police institutions in managing information. However, due to the sensitivity of police operations, custom made applications are often preferred to commercial of-the-shelf products. A number of existing Information systems are discussed in the next section.

The IMS has to be developed based on the business needs of the organization that will use it. Using the developed business processes, a model or architecture can then be developed from which the application will then be developed [8]. By carefully analyzing the needs of the organization in 
question, it is possible to optimize some of the bottlenecks in their operations. This can also help identify the services that are required for third party communications with outside parties [8] as well as redundant ones.

Case management is an example of the type of information that the police make use of on a daily basis [4]. It is important that the implemented system also implements the various processes associated with it. This involves identifying the actors and how they interact to perform various functions [4], [5]. The main operations here include the flow of information from the time a crime is reported at the reception, and then assigned to an Investigator, on to the prosecution and finally the adjudication [4].

Most police systems integrate biometrics [9]-[13]. Biometrics is one of the fast growing fields that are applied in forensics and investigations [6]. This field concentrates on the identification of individuals based on their biological traits [14], [15]. There are different types of Biometrics that include Fingerprint, Hand scan, Signature, Iris, Retina, Voice and Face [16]. Fingerprint Biometrics dates as far back as the $19^{\text {th }}$ Century in which fingerprints were collected using physical card files for comparison. It has undergone various advancements since then making it one of the most mature biometric technologies around [6].

The proposed solution aims to document and automate the business processes of criminal and non-criminal activities. Fingerprint Biometrics has been chosen as part of the automation process because it fits into what is currently collected. Secondly, it is one of the most mature technologies as already established with lots of research going into the fields of Image Enhancement, Feature Extraction, and Identification and Verification algorithms [15]-[25].

Various Biometric products exist on the market today most of which are accompanied by a Software Development Kits (SDK). An SDK enables a Software Programmer to create software applications that communicate with the specific hardware for which it is written. Most of the available SDKs are commercial. The most common vendors are Verifinger, Microsoft, MorphoTrak, Crossmatch, 3M Congent and Pradotech [26], [27].

\section{B. Related Works}

A number of systems have been developed to aid with the capture, use and sharing of vital information for the security wings is various countries. One such system that allows five countries to share biometric information is the Secure Real Time Platform [9]. This is used to track international fugitives as they move from one country to another. United States of America (USA), United Kingdom (UK), Canada, Australia and New Zealand use this system. The following are some more examples of systems that various governments have implemented for this purpose.

There are plans underway between the government of Argentina and CrossMatch to deploy Identity Management Systems throughout the country [10]. CrossMatch offers both fingerprint and palm print biometrics. The support of law enforcement agencies includes criminal booking, civil applicant background check and multi-factor authentication before accessing sensitive applications and the network.

The Canadian government is currently using MorphoBIS software developed by Morpho in two police stations that have adopted the solution for paper-less responses and real time identification [10]. This system integrates the use of Fingerprint and Palm Print and will add Iris recognition in future. The system has also been designed to interoperate with other systems such as Automated Fingerprint Identification System (AFIS). The system has been built using a Service Oriented Architecture (SOA) and works with Oracle 11g database.

The Federal Bureau of Investigation (FBI) upgraded the old Integrated Automated Fingerprint Identification System (IAFIS) to the Next Generation Identification (NGI) System in 2014 [11]. In addition to Fingerprint and Palm Print, NGI also introduces Facial Recognition and Rapid DNA analysis.

Another system known as FaceSketchID has been developed by a team of researchers. This system is used to match suspect sketches with mugshot database images [12].

In Australia, the National Automated Fingerprint Identification System (NAFIS) provides police agencies with fingerprint data [13]. NAFIS will soon be replaced with a system that captures more biometrics.

\begin{tabular}{|c|c|c|}
\hline Name & Features & Country \\
\hline Secure Real Time Platform & Fingerprint & $\begin{array}{l}\text { USA, UK, } \\
\text { Canada, Australia } \\
\text { and New Zealand }\end{array}$ \\
\hline $\begin{array}{l}\text { Identity Management } \\
\text { Systems }\end{array}$ & - & Argentina \\
\hline MorphoBIS & $\begin{array}{l}\text { Fingerprint / Palm } \\
\text { print }\end{array}$ & Canada \\
\hline $\begin{array}{l}\text { Integrated Automated } \\
\text { Fingerprint Identification } \\
\text { System (IAFIS) }\end{array}$ & $\begin{array}{l}\text { Fingerprint / Palm } \\
\text { print }\end{array}$ & USA \\
\hline $\begin{array}{l}\text { Next Generation } \\
\text { Identification (NGI) }\end{array}$ & $\begin{array}{l}\text { Fingerprint / Palm } \\
\text { print / Rapid DNA } \\
\text { Analysis / Face }\end{array}$ & USA \\
\hline FaceSketchID & Face & USA \\
\hline $\begin{array}{l}\text { National Automated } \\
\text { Fingerprint Identification } \\
\text { System (NAFIS) }\end{array}$ & Fingerprint & Australia \\
\hline
\end{tabular}

Table I shows the existing government systems showing the features that have been implemented.

From the above systems, it is clear that there is significant benefit in having automated information systems especially when to comes to local and international crime investigations. It is also clear that these solutions have been implemented mostly in the developed world. To implement the same systems in a developing country would call for a lot of adjustments and customization due to the fact that certain assumptions may not hold true.

The following are examples of systems that have been developed in Africa in similar conditions to those of Zambia, the focus are of this study.

The Makerere University of Uganda, through the ARMS project, developed the Uganda Police Force Crime Records Management System (PFCR). This is a crime records system whose prime purpose is to improve the performance of the crime records management in the Ugandan police. It was motivated by the limited capacity for tracking cases, lack of crime intelligence, possible manipulation of crime records and lack of a mechanism for retrospective support. The main 
areas of interest for the system are the crime intelligence and investigations, the traffic department and the minor contraventions department. An example of a business case in the crime investigations department is the process from the time a new case is reported to the time a case is closed [4].

Another system that was developed in Uganda is the Traffic Case Management System (TCRIS) [5]. Unlike PFCR, TCRIS has a specific focus on the management of Traffic Case documents. The main purpose was to automate the processes that were being handled using paper based mechanism. The system has a centralized database that can be accessed by the Migrations Department, Bank of Uganda and the Uganda Revenue Authority. The system is developed using Visual basic on the front-end and SQL Server 2005 on the backend.

The proposed solution presented in this paper aims to tackle the following areas.

1) Identification of major police business processes

2) Development of a web interface to capture both criminal and non-criminal data based on the business processes identified.

3) Integration of Automated Fingerprint Biometric capture into the Police's current mode of operation.

\section{Methodology}

\section{A. Baseline Study}

This study employed a mixed approach of both qualitative and quantitative analysis. This was necessitated by the nature of the data required for the research. Questionnaires were distributed to gather information. In addition, a repeated set of oral interviews were also conducted.

Zambia is a landlocked sub-Saharan country that shares a border with eight countries. The country has an area of 752 , $612 \mathrm{~km}^{2}$ [28] and a population of approximately 15.5 million people [29]. The country has ten provinces, two of which are predominantly urbanized, that is Lusaka and Copperbelt provinces [28]. This study was conducted in Lusaka the capital city of Zambia. Lusaka has a population density of 100 people per square kilometer with an approximate population of 2.8 million people [29].

There are over twenty police stations within. Sixty five (65) questionnaires were distributed to eight (8) police stations within Lusaka. The criterion for choosing the stations was based on their size and location. Four big police stations and four smaller stations were chosen. This was done in order to capture business processes from the different type of police institutions. Microsoft excel spreadsheet was used to analyze the data after collection.

\section{B. Software Development}

An Agile Software Development Life Cycle (ASDLC) was chosen due to the constant interaction with the end-user. This allows for implementation of new features that are packaged into a prototype at the end of every cycle or sprint in order to get more feedback on how to improve the product or clear out any issues relating to misunderstanding in the interpretation of requirements. Fig. 1 shows the Agile SDLC process [30].

The system has been developed using Java Server Pages
(JSP), MySQL database and runs on an Apache Server. The NetBeans Integrated Development Environment was used for the development process.

Additionally, the Griaule Software Development Kit (SDK) was used for the development of the Fingerprint Subsystem. The captured fingerprints are pre-processed using wavelet scalar quantization (WSQ) algorithm that has been certified by the FBI on different platforms [31]. The minutiae are extracted and a template generated using the Delaunay triangulation [32] that employs triangulation and geometry relation between minutiae. This has been tested with the DigitalPersonaU4500 but is expected to work well with any device that is supported by Griaule SDK.

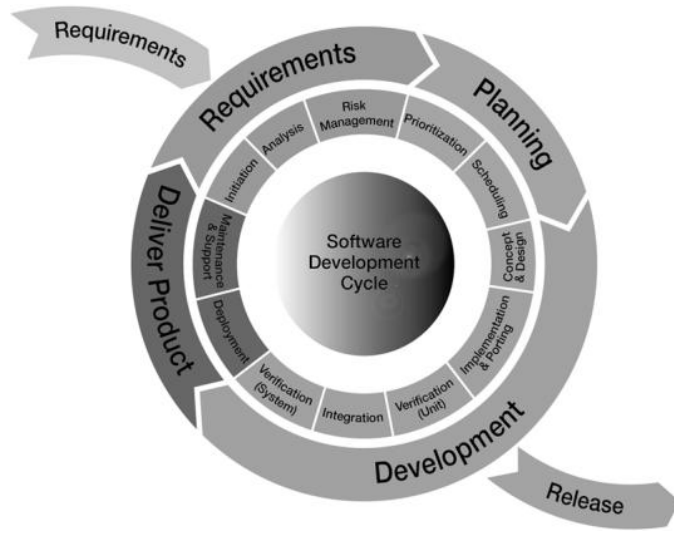

Fig. 1. Agile software development life cycle.

\section{Business Process Mapping}

The system under development is a 3 Tier Application comprising the user interface on the client, business logic, and the database on the server. Fig. 2 shows the context architectural diagram for the system.

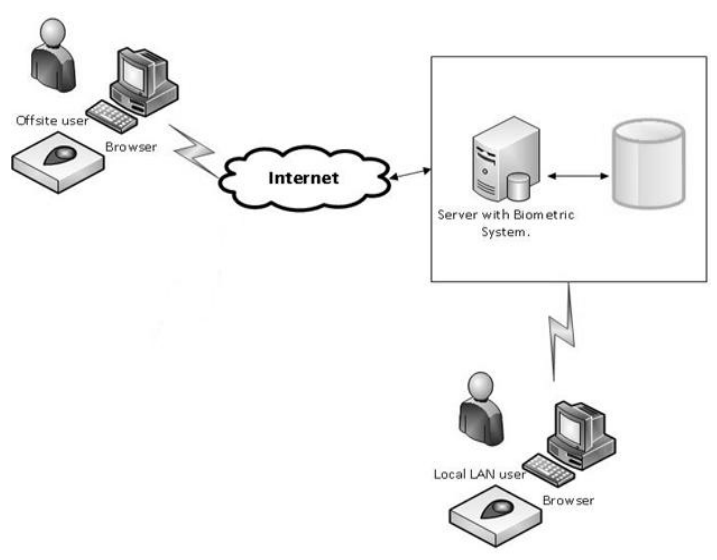

Fig. 2. Context architectural diagram of the proposed system.

There are two modes of accessing the system. The first is through the internet and the second is direct connection over the network depending on where the system has been deployed. Any user wishing to capture biometric information needs to have a fingerprint reader connected to their computer as they open the system.

There are four primary actors that have been identified as potential users of the system at the police stations. These are the Enquiries Officer, Records Officer, Criminal Investigation Detective, and the Criminal Investigation Officer. 


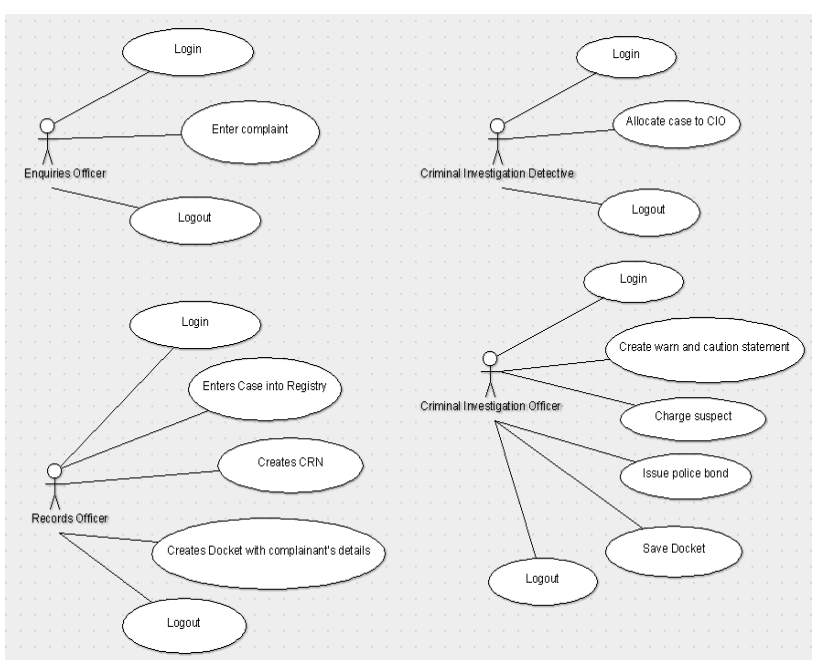

Fig. 3. System use case diagram.

Fig. 3 is a use case diagram depicting some of the functionality that the users of the prototype can access based on the information that has been collected so far. In terms of security, Role-Based Security is adopted for implementation to allow users to only access functionality that they need for their day to day operations. This is because people with different roles within the police typically perform various functions. Certain functions are hidden from users without the required permissions.

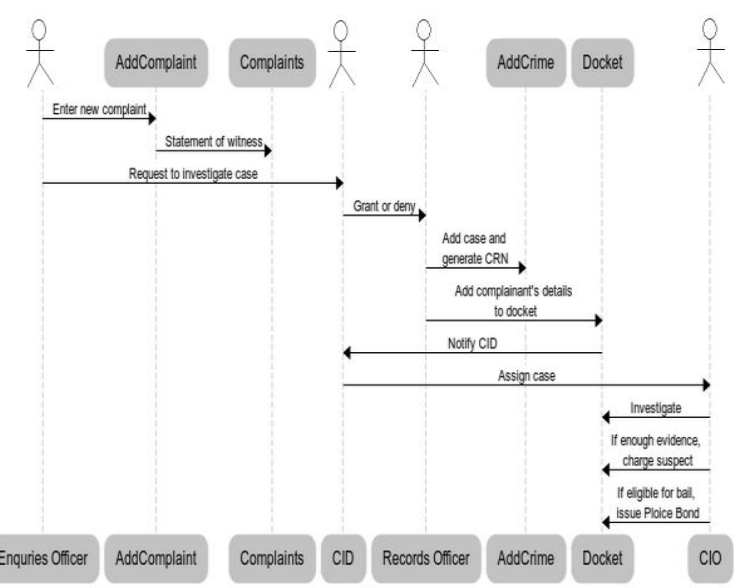

Fig. 4. Sequence diagram showing how a case is assigned.

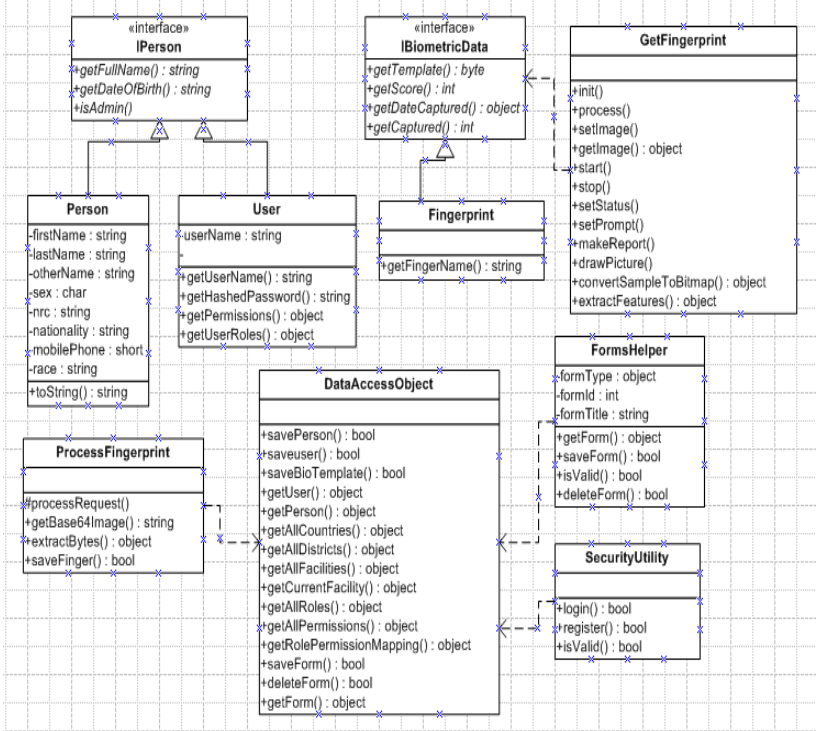

Fig. 5. Class diagram.
Fig. 4 shows a flow diagram for a specific business process of assigning a criminal case and how the different users interact with one another from the moment a complaint is recorded.

Fig. 5 shows the Class diagram depicting some of the classes that have been developed in the system based on the paper tools that were provided by the Police. The Persons and User class represent the Person and user entities in the application. They both share common operations from the interface IPerson.

The DataAccessobject class is responsible for communicating with the database directly. The FormsHelper class is a generic class that handles saving of forms to the database.

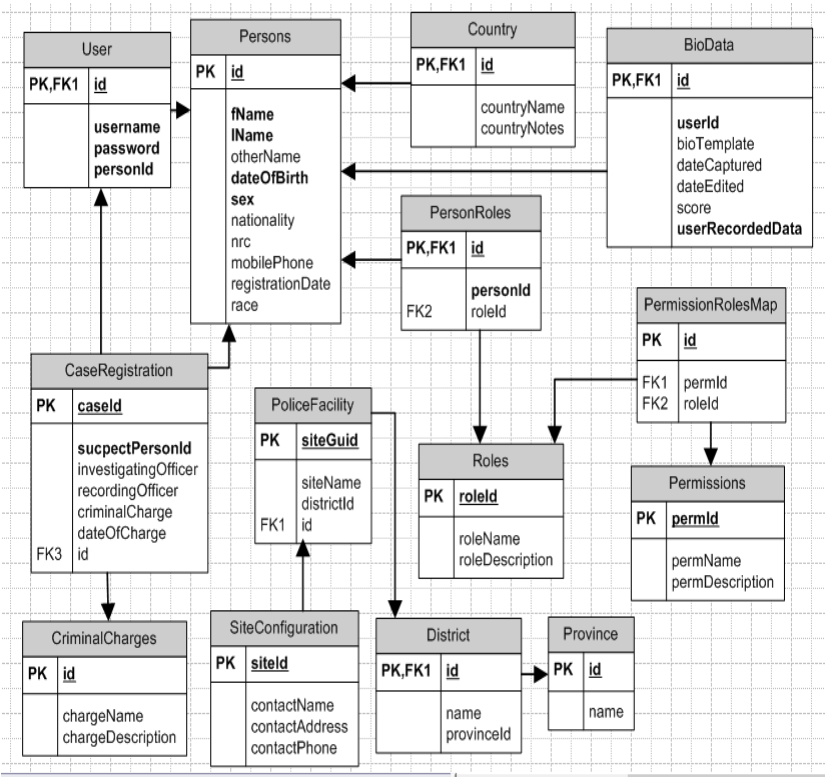

Fig. 6. Entity Relationship diagram showing some of the entities of the prototype.

Fig. 6 shows the Entity relationship diagram for the prototype. The different sections can be grouped into five broad categories. These are security, person tables, biometric data, police site settings, and case management tables. The relationships between the different tables are also illustrated in the diagram above.

\section{RESULTS}

The main purpose of the survey was to determine if the system can be used in the current setting of the Zambia police service. Suffice to mention that there is need for ICT skills in order to use the system. The research thus focused on the levels of ICT skills as well as the highest level of education reached.

\section{A. Highest Education Level Reached}

From the results in Fig. 7, 47\% attained college education. A combined total of $21 \%$ has completed Graduate and/or Postgraduate education. However, there is a $32 \%$ that has gone as far as high school.

\section{B. Training Opportunities and ICT Infrastructure}

As shown in Fig. 8, 24\% of the respondents have received formal basic computer training in the past. Although this is 
less than $50 \%$ of the respondents, it is worth noting that the number of officers with access to development opportunities is at $5 \%$. Information management systems training are at $10 \%$ whereas Cyber-security testing is at $7 \%$. Another important thing to note is that people with access to Internet and Research facilities are $10 \%$ of the respondents.

\section{Use of ICTs in Police Stations}
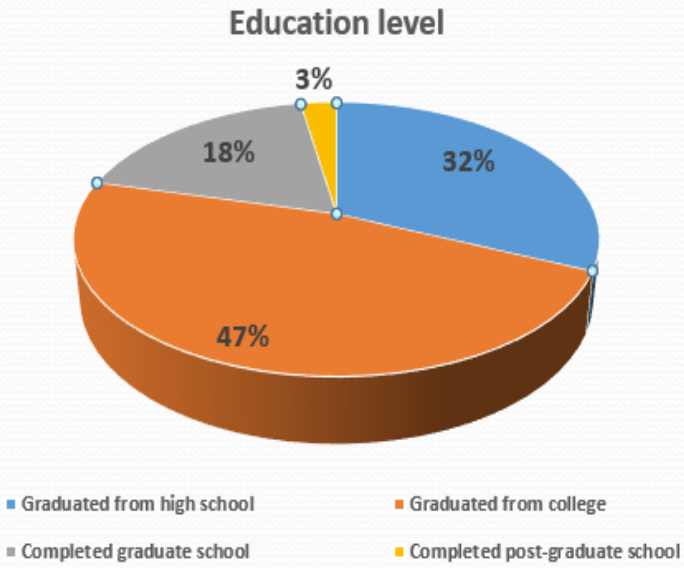

Fig. 7. Highest education level.

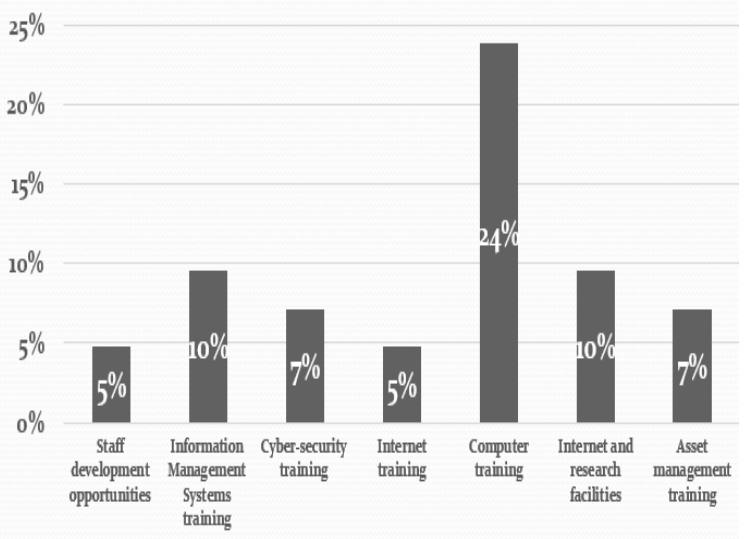

Fig. 8. Training opportunities and ICT infrastructure availability.
Uses personal email for work communications

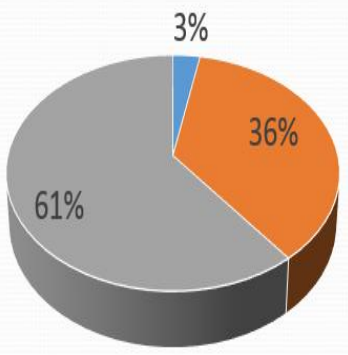

IAlways $\|$ Sometimes $\|$ Never
Uses personal devices for work documents

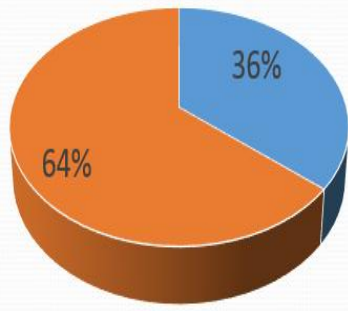

- Yes $\|$ No
Fig. 9. Use of ICTs in police stations.

From Fig. 9, 39\% use their personal email for work related communications. Additionally, 36\% use their personal devices to store work related documents. This practice poses a threat to national security especially when highly sensitive information is involved. This can be avoided by implementing and enforcing strict ICT policies and guidelines. The identified missing policies are email and network policies as well as Bring Your Own Device (BYOD) standards.

\section{Prototype Development}

The prototype has been developed as a web based platform using Java web technologies. The application uses a MySQL database backend and has Java Server Page front end with JavaScript used for front-end validations.
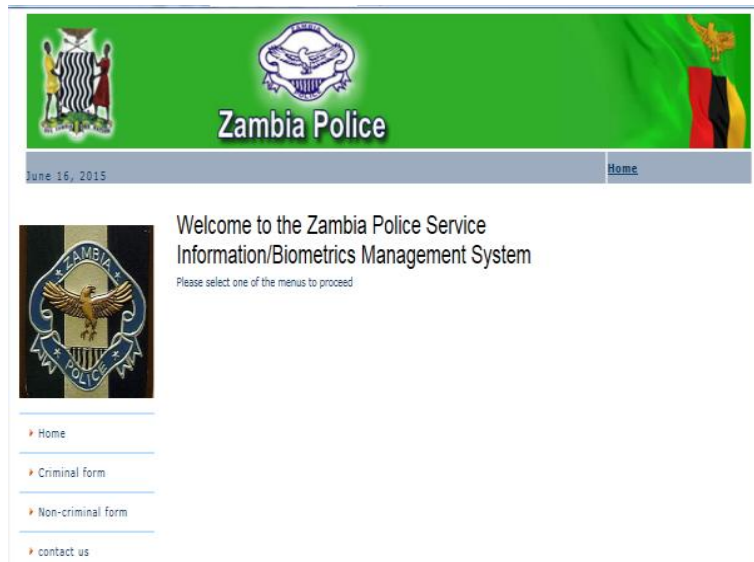

Fig. 10. The home page for the application after logon.

Fig. 10 shows the home screen for the application after a user has logged in, the user is presented with two forms on this screen, one for criminal use and the other for non-criminal use.

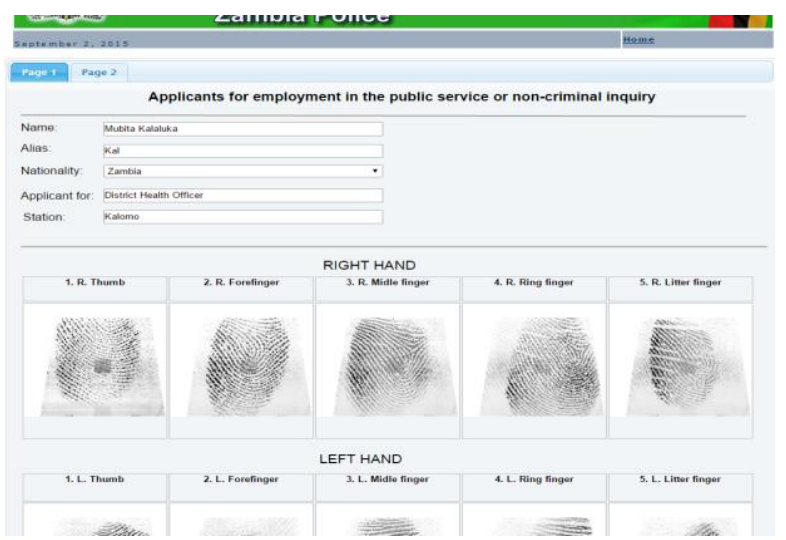

Fig. 11. Screen showing the form that is filled out for non-criminal use.

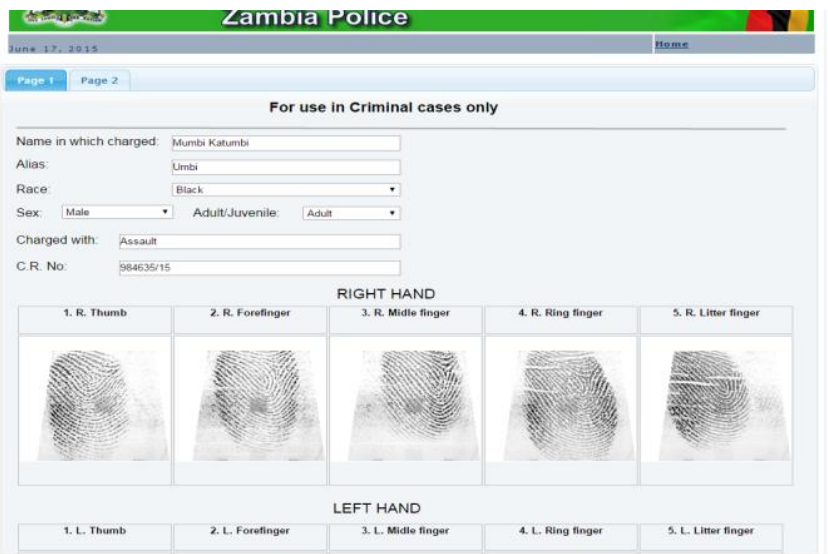

Fig. 12. Screen showing capture of fingerprints from the system.

Fig. 11 shows the non-criminal form in the application. This form is required by the Zambian government when someone is being hired into a public service job. The form first collects basic bio-data for the person before the biometric data is captured. All the ten fingerprints are captured and in addition to that, an impression of all the fingers captured 
together is also collected. This is currently not supported by the prototype.

Fig. 12 shows the criminal form. Most of the details that are captured on this form are similar to those on the non-criminal form with minor differences like the details of the offense. On the same form, we also show all fingerprints of the right hand captured by the prototype

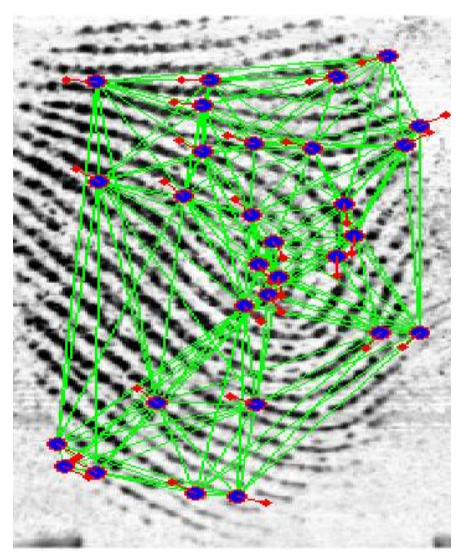

Fig. 13. Screen showing capture of a fingerprint template using the Delaunay algorithm.

Finally, Fig. 13 shows how the minutiae are extracted from the fingerprints in the captured system. This process of feature extraction is handled by the use of the Delaunay algorithm. The template that is created is then saved in the database and can later be used for matching purposes.

The two forms shown above are some of the most widely used forms in the registry. More forms specific to processes like case management are yet to be included in the prototype.

\section{DISCUSSION AND CONCLUSION}

According to the results of this research, $68 \%$ of the respondents went as far as college at least. The remaining $32 \%$ only went as far as high school. We can loosely infer that the people falling in the $68 \%$ umbrella have used a computer at some point during their training. This was important because the learning curve for someone with prior computer training is easier to train in a specific computer application than one with no prior computer training.

However, as can be seen from Fig. 6, only $24 \%$ of the respondents have received computer training. It was expected that this number will be much closer to $68 \%$. One reason why this is not so may be because we captured only those who have formally been trained in basic computing. This obviously leaves out people who have computer knowledge but lack formal training. Suffice to say that other respondents pointed out their prior training in Information management systems, cyber security and asset management systems.

Two other low statistics from the results are staff development opportunities, and internet and research facilities. These came at $5 \%$ and $10 \%$ respectively. The lack of these facilities is bound to have a negative impact on the development of the police officers and indirectly on their work as a whole.

Another major concern is that of usage of personal emails and devices for work related documents. 39\% use their personal email for work communications. Additionally, $36 \%$ use their personal devices for work related documents. This is a big security concern considering that most information that is shared within the police service is confidential.

Finally, a prototype has been developed that allows a user to enter both criminal and non-criminal related information. This has been implemented using Java. It also has integration of fingerprint biometrics. In future, more biometrics will be included to support other functions of the police.

In this study, we proposed the automation of business processes for the Zambia Police Service as a third world country. However, various other applications can benefit from this including education, health care and banking. Based on the outcome of this research, it is recommended that the Police Service should adapt and implement the National ICT Policy. It is also recommended that the government should build more capacity in the human resource and infrastructure for the Zambia Police Service.

The baseline study was carried out to establish the skill and level of utilization of ICTs. A prototype was then designed and implemented which integrates biometrics.

\section{FUTURE WORKS}

A number of business processes have been implemented in this research study. However, there is some functionality that has not been implemented.

In future, the prototype should be extended to cover the following;

- Addition of palm print biometrics for data capture as this is currently done using paper systems

- Integration of facial recognition component to allow matching of suspects' mugshots with mugshot databases.

- Development of a comprehensive case management component

\section{ACKNOWLEDGMENT}

The authors would like to thank the Zambia Police Service for allowing them to carry out this research.

\section{REFERENCES}

[1] A. Abubakar and R. Tasmin, "The impact of information and communication technology on banks' performance and customer service delivery in the banking industry," International Journal of Latest Trends Fin. Eco. Sc., vol. 2, no. 1, pp.80-90, 2012.

[2] A. S. Rwashana and D. W. Williams, "Enhancing healthcare delivery through ICTs: A case study of the Ugandan immunisation system," International Journal of Education and Development Using Information and Communication Technology (IJEDICT), vol. 4, no. 2, pp. 144-158, 2008.

[3] Y. Gülbahar, "ICT usage in higher education: A case study on preservice teachers and instructors," Turkish Online Journal of Educational Technology, vol. 7, no. 1, pp. 32-37, 2008.

[4] A. Muyanja et al., "Requirements engineering for the Uganda police force crime records management system," in Proc. 2013 21 st IEEE International Requirements Engineering Conference, 2013, pp. 302-307.

[5] C. M. Mubaraka, I. M. Jirgi, and P. L. B. Nanyanzi, "Integrating ICT in traffic police department in Uganda: Design and development of traffic case management system (TCRIS)," vol. 4, no. 5, pp. 17-27, 2013.

[6] R. Kaur, P. S. Sandhu, and A. Kamra, "A novel method for fingerprint feature extraction," in Proc. 2010 International Conference on Networking and Information Technology (ICNIT), June 2010, pp. 1, 5, 11-12. 
[7] Business Information and ICT. Costs and benefits of ICT. [Online]. Available:

http://www.bbc.co.uk/bitesize/higher/business_management/business _enterprise/business_information_ict/revision/6/

[8] R. D. Zota and L. Ciovica, "Designing software solutions using business processes," Procedia Economics and Finance, vol. 20, no. 15 pp. 695-699, 2015.

[9] Global moves to extend the scope of national biometric identification systems, Biometric Technology Today, vol. 2013, issue 1, January 2013.

[10] Canadian police get real-time fingerprint and palm ID system, Biometric Technology Today, vol. 2011, issue 6, June 2011, p. 12.

[11] FBI NGI goes live with new biometric capabilities, Biometric Technology Today, vol. 2014, issue 10, October 2014, pp. 1-2

[12] Police forces across the globe implement biometric tech, Biometric Technology Today, vol. 2015, issue 1, January 2015, p. 1.

[13] Police forces extend use of biometrics across the globe, Biometric Technology Today, vol. 2014, issue 9, September 2014, p. 3.

[14] V. Andronikou, S. Xefteris, and T. Varvarigou, "A novel, algorithm metadata-aware architecture for biometric systems," in Proc. 2012 IEEE Workshop on Biometric Measurements and Systems for Security and Medical Applications (BIOMS), pp. 1, 6, 14, Sept. 2012.

[15] M. D. Femila and A. A. Irudhayaraj, "Biometric system," Electronics in Proc. 2011 3rd International Conference on Computer Technology (ICECT), vol. 1, pp. 152, 156, April 8-10, 2011.

[16] S. K. Mitra and P. Munshi, "Reconnecting broken ridges in fingerprints," in Proc. 2012 Third International Conference on Emerging Applications of Information Technology (EAIT), Nov. 30, 2012, pp. 275, 278

[17] J. Wang, H. Shen, and R. Ding, "A novel fingerprint image enhancement algorithm using phase preserving," in Proc. IEEE International Symposium on Communications and Information Technology, vol. 2, Oct. 12-14, 2005, pp. 1472, 1475.

[18] Y. Zhang and X. Jing, "Spectral analysis based fingerprint image enhancement algorithm," in Proc. 2010 International Conference on Image Analysis and Signal Processing (IASP), April 9-11, 2010, pp. $656,659$.

[19] S. Vaikole, S. D. Sawarkar, S. Hivrale, and T. Sharma, "Minutiae feature extraction from fingerprint images," in Proc. IEEE International on Advance Computing Conference, March 6-7, 2009, pp. 691,696

[20] M. J. Asha, "A novel algorithm for fingerprint identification using ellipse method," 2013 Fourth International Conference on Computing, Communications and Networking Technologies (ICCCNT), July 4-6, 2013, pp. 1,4

[21] A. J. Basha, V. Palanisamy, and T. Purusothaman, "Fast multimoda biometric approach using dynamic fingerprint authentication and enhanced iris features," in Proc. 2010 IEEE International Conference on Computational Intelligence and Computing Research (ICCIC), Dec. 28-29, 2010, pp. 1, 8 .

[22] W. Wang and L. Sun, "A fingerprint identification algorithm based on wavelet transformation characteristic coefficient," in Proc. 2012 International Conference on Systems and Informatics (ICSAI), May 19-20, 2012, pp. 1, 3

[23] M. S. Khalil, D. Muhammad, and Q. Al-Nuzaili, "Fingerprint verification using the texture of fingerprint image," in Proc. Second International Conference on Machine Vision, Dec. 28-30, 2009, pp. 27,31
[24] U. K. Bhowmik, A. Ashrafi, and R. R. Adhami, "A fingerprint verification algorithm using the smallest minimum sum of closes Euclidean distance," in Proc. International Conference on Electrical, Communications, and Computers, Feb. 26-28, 2009, pp. 90, 95.

[25] M. A. Medina-Perez, M. Garcia-Borroto, A. E. Gutierrez-Rodriguez, and L. Altamirano-Robles, "Robust fingerprint verification using M-Triplets," in Proc. 2011 International Conference on Hand-Based Biometrics (ICHB), Nov. 17-18, 2011, pp. 1, 5 .

[26] Find Biometrics. (Jan. 11, 2015). Biometrics Hand/Palm scanners and finger readers. [Online]. Available: http://findbiometrics.com/solutions/hand-readers-finger-scanners/

[27] Biometric Update. (Jan. 11, 2015). Biometric companies. [Online]. Available: http://www.biometricupdate.com/biometric-companies

[28] (Aug. 30, 2015). Zambia demographic and health survey 2013-14 report. [Online]. Available: http://www.dhsprogram.com/pubs/pdf/FR304/FR304.pdf

[29] Zambia Demographics at a Glance. (Aug. 30, 2015). Zambia demographics at a glance. [Online]. Available: http://zambia.opendataforafrica.org/efhbnl/zambia-demographics-at-a -glance

[30] Agile Software Development. (Aug. 15, 2015). Agile software development. [Online]. Available: http://www.tara-systems.de/tl_files/content/about_us/images/sw_dev _process_header.png

[31] Griaule AFIS WSQ SDK. (Aug. 15, 2015). Griaule AFIS WSQ SDK. [Online]. Available: http://www.mantratec.com/Biometrics-Forensic-Solutions-Griaule-A FIS-WSQ-SDK.html

[32] G. Bebis, T. Deaconu, and M. Georgiopoulos, "Fingerprint identification using Delaunay triangulation," in Proc. International Conference Information Intelligence and Systems, 1999, pp.452-459.

G. Lyoko was born in Mongu, Zambia on May 10, 1988. He received his bachelor's degree in software engineering from the University of Zambia (UNZA) in 2010. He is currently working as a senior software developer for Zambia's electronic health record system (EHR) called SmartCare. He is a member of Association for Computing Machinery (ACM). His research interests include artificial intelligence, biometrics and mobile computing.

J. Phiri is currently working for the University of Zambia in the Department of Computer Science. He is the current chair of the Department of Computer science at the University of Zambia. He obtained his bachelor of computer Science at the University of Zambia in 2004, an MSc in computer science at the University of the Western Cape in South Africa in 2007 and a PhD in computer science at Harbin Institute of Technology in China in 2012. His research interest include identity management, data mining, applied artificial intelligence technologies and information security.

A. Phiri is currently working for the Zambia Airports Corporation Limited, as the head of ICT department. He obtained his bachelor of engineering at the University of Zambia in 2005, and currently pursuing a MEng in ICT Policy, regulation and management at the University of Zambia. He is a fellow member of the Engineering Institution of Zambia. He is also a member of the IEEE and ACM. His research interests include telecommunication policy and regulation, food supply chain management and computer communication systems. 